\title{
Tinjauan Buku
}

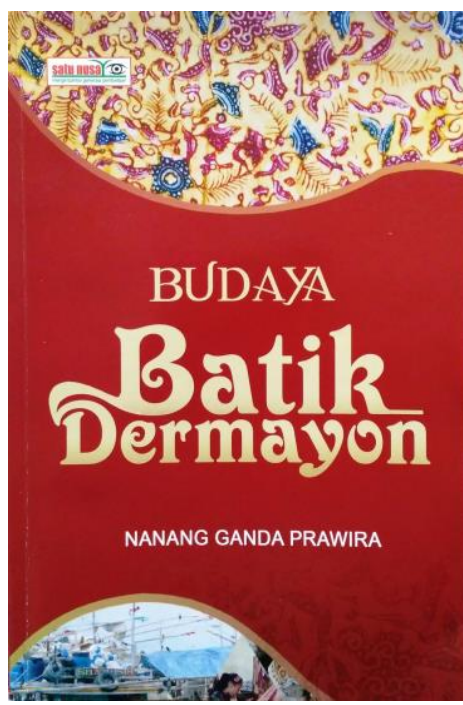

\begin{tabular}{|c|c|}
\hline Judul Buku & : Budaya Batik Dermayon \\
\hline Penulis & Nanang Ganda Prawira \\
\hline Penerbit & Satu Nusa \\
\hline Tahun & 2018 \\
\hline Halaman & $: \quad x+294$ halaman \\
\hline
\end{tabular}

\section{Ekspresi Perempuan dalam Batik Pesisir Indramayu}

Buku berjudul "Budaya Batik Dermayon" ini menyajikan deskripsi dan analisis mengenai seni batik pesisiran Indramayu melalui kaca mata estetika dan semiotika. Buku ini merupakan hasil penelitian yang dilakukan oleh Prawira, seorang dosen pada jurusan seni rupa di Universitas Pendidikan Indonesia dengan latar belakang pendidikan di bidang seni rupa dan kajian budaya. Prawira melakukan penelitian lapangannya pada tahun 2013 di Kelurahan Paoman, Indramayu, Jawa Barat. Penelitiannya itu "berupaya untuk memaknai motif-motif batik Dermayon ini sebagai wujud ekspresi perempuan sebagai bagian dari budaya masyarakat pesisir" (h.13).

Struktur penulisan buku ini terpilah menjadi lima bab yang narasinya tercermin pada judul setiap bab-nya. Pada bab I, dibuka dengan judul 'Pengantar: Latar Belakang Budaya dan Eksistensi Batik Dermayon'. Sebagai bab pendahuluan, bagian ini memaparkan latar belakang penelitiannya dan posisi penelitian ini di antara penelitian mengenai batik Indramayu yang telah dilakukan oleh peneliti lain sebelumnya; state of the art dari penelitiannya. Dalam bab ini didiskusikan kerangka konseptual sebagai kerangka berpikir dalam melakukan penelitian mengenai batik Indramayu (Dermayon) ini. Pada bagian ini diulas beberapa konsep mengenai seni kriya batik, budaya batik pesisiran, peran perempuan dalam budaya batik dan semiotika. Konsep-konsep tersebut menjadi alat bantu yang digunakan Prawira ketika mencari dan memilah data, serta menjadi pisau analisis untuk membahas temuan-temuan data penelitiannya.

Bab II yang berjudul "Masyarakat dan Budaya Pesisiran Indramayu" memberikan ulasan mengenai gambaran umum mengenai konteks di mana batik Dermayon hadir dan berkembang pada ruang, waktu, dan budaya masyarakat pesisir utara Jawa. Paparannya dimulai dengan aspek sejarah, demografis, geografis, sosial dan budaya di Indramayu pada umumnya, serta Kelurahan Paoman khususnya sebagai lokasi studi. Pada dua sub bab akhir di bab ini, diulas mengenai ragam kesenian sekaligus hiburan rakyatnya dan 
peran perempuan dalam kesenian di Indramayu. Paparan tersebut menjadi dasar sekaligus jembatan untuk memahami bacaan bab selanjutnya.

Dua bab selanjutnya, yaitu bab III dan IV merupakan bahasan inti dari buku ini, Isinya mengenai deskripsi dan analisis terkait budaya batik Dermayon sebagai ekspresi dari perempuan pesisir utara Jawa. Bab III diberi judul "Batik Dermayon dan Peran Perempuan Pekriya dalam Budaya Pesisiran Indramayu". Batik Indramayu atau disebut juga batik Dermayon atau Dermayuan mengacu pada identitas nama daerah Indramayu. Dalam lintasan sejarahnya sebagai wilayah pelabuhan, Indramayu menjadi ruang akulturasi budaya lokal dengan budaya dari Jawa Tengah, Jawa Tmur, Arab, Cina dan Eropa. Hal tersebut berpengaruh juga pada budaya batik Dermayon yang merupakan "ekspresi budaya pesisiran" (h.102) yang terlihat dari tema dan bentuk motif hias batiknya. Selain itu, pada bagian ini, digambarkan dengan detail peralatan dan bahan pembuatan batik, serta teknik dan sistem teknologi untuk membuat batik. Di samping juga diulas mengenai pembagian kerja dan peran perempuan pekriya dalam sistem produksi dan dalam pengelolaan usaha batik.

Analisis estetik pada bab III ini, difokuskan pada motif batiknya yang dikategorikan menjadi tiga, yaitu berdasarkan tema, unsur visual dan struktur estetik. "Pada umumnya motif batik Dermayon merupakan paduan antara motif tumbuhan, binatang, alam benda, peristiwa dan pengolahan bentuk geometris" (h.145). Dari segi tema motif batik Dermayon terungkap ada 45 jenis motif batik yang dianalisis, baik tema yang sudah lama ada, maupun tema yang baru dikreasikan. Motif yang diulas tersebut di antaranya ialah motif beras ketumplek, kembang kol, jati rombeng, iwak etong, liong, poyong, mangga, srintil, obar-abir, sejuring dan lain sebagainya. Deskripsi dan uraian analisis motif batik tersebut dibuat dalam bentuk tabel dan disertai gambar berwarna, sehingga membantu pembaca untuk cepat menangkap maksud dari pemaparan penulis.

Bahasan penulis pada bab IV yang berjudul "Makna Motif Batik Dermayon" merupakan kelanjutan analisis estetik dari bab sebelumnya, dan menambahkan secara kontekstual analisis semiotik untuk mengungkapkan makna dari motif batik Dermayon. Prawira menemukan bahwa perempuan pekriya batik Dermayon mengekspresikan kreativitasnya dalam membatik dengan membuat motif yang berbeda, namun masih tetap mengacu pada bentuk-bentuk lama yang telah ada. Seperti yang ditulis Prawira bahwa "motif batik yang baru tidak berarti menciptakan yang 'baru sama sekali', tetapi kombinasi baru atau reintegrasi atau pengubahan (modifikasi) dari motif-motif yang sudah ada" (h.192). Di samping itu, motif batik Dermayon memiliki tanda visual unik dan khas yang menjadi "Identitas budaya visual pesisiran" (h.247). Misalnya motif flora dan fauna yang tumbuh dan hidup di sekitar wilayah pesisir dan laut, serta motif gejala alam, dan artefak yang ada di lingkungan sekitar seperti ombak laut dan kapal nelayan, ada pula motif isen-isen (sisik, garis lengkung dan spiral). Tanda visual itu tercermin dalam unsur garis, bentuk, warna dan komposisinya yang maknanya berhasil didedah secara apik melalui analisis estetik dan semiotik dalam konteks budaya (perempuan pesisir) Indramayu.

Bab terakhir, yaitu bab V yang diberi judul "Penutup: Batik Dermayon sebagai Wujud Ekspresi Perempuan dan Budaya Pesisiran". Bab V merupakan bagian kesimpulan dari buku ini yang menegaskan temuan penelitian dan tesis utama dari seluruh pembahasan buku ini.

Buku ini merupakan hasil kajian yang menarasikan, mendeskripsikan serta menganalisis seni batik pesisir Indramayu secara tekstual sekaligus kontekstual. Penulis buku ini melakukan pembacaan tekstual dari estetika karya visual seni kriya batik; serta kontekstual dari budaya perempuan pesisir. Dalam hal ini penulisnya menggunakan pendekatan deskriptif untuk seni batik, yang bertujuan untuk menggambarkan dan 
menguraikan fenomena yang diteliti; serta pendekatan semiotik yang melihat suatu fenomena sebagai tanda-tanda untuk ditafsirkan makna (relasi antartanda) nya.

Dalam teknis penulisan dan penyajian buku ini terbilang baik, karena dilengkapi dengan dengan tabel-tabel kategorisasi yang memudahkan pembaca untuk cepat memahami apa yang menjadi inti temuan dan analisa hasil penelitiannya. Di samping itu, foto-foto berwarna yang ditampilkan di dalam buku, membantu memahami deskripsi yang ada dan menjelaskan dengan detail melalui visualisasi dalam pembahasan mengenai seni batik yang berbasis rupa ini.

Buku ini, pada satu sisi bermanfaat dalam hal dokumentasi dan inventarisasi budaya batik di Indramayu. Analisanya menumbuhkan pemahaman baru terkait kajian seni yang kontekstual, dalam hal ini konteks peran perempuan pekriya di wilayah pesisiran. Buku ini dapat menjadi inspirasi bagi kerja-kerja dokumentasi dan inventarisasi terkait artefak budaya yang selalu memiliki sisi nilai budayanya (intangible in tangible culture), sekaligus juga pada kajian-kajian terhadap artefak budaya lainnya dan/atau di wilayah budaya lainnya.

Kekurangan buku ini ialah kurang diulasnya peran laki-laki dalam budaya batik Dermayon, meskipun hal ini secara implisit telah disadari dan merupakan pilihan penulisnya yang memfokuskan kajian pada konteks budaya perempuan pesisir. Secara umum buku ini layak untuk dibaca dan dimiliki oleh peminat dan pengkaji seni dan budaya; serta instansi pemerintah maupun lembaga lainnya yang berkecimpung dalam bidang kebudayaan (Arief Dwinanto). 